\title{
Endogenous Retrovirus
}

National Cancer Institute

\section{Source}

National Cancer Institute. Endogenous Retrovirus. NCI Thesaurus. Code C14334.

Genetic elements propagated primarily through the germline, with a proviral structure, i.e. the chromosomally-integ rated form of retroviruses and regulated by cellular processes. Could be involved in development and serve as progenitors to pathogenic retroviruses. Classified as ecotropic or xenotropic. Ecotropic viruses can be transmitted to cells of the same species and can produce malignancies. Xenotropic viruses cannot infect cells from their host species but are infectious in heterologous species. Cycles of transcription and reverse transcription make the elements mobile and mutagenic. 